\title{
Management of coarctation of the aorta in the first six weeks of life
}

\author{
G. MEREDITH, R. SAW YER, a nd M. V. BR A I M B R I G E \\ Department of Cardiothoracic Surgery, St. Thomas' Hospital, London, S.E.1
}

\begin{abstract}
The position of surgery in the management of coarctation of the aorta in infants under 6 weeks of age is still not established, primarily because of the high mortality associated with resection of the coarctation. Five patients with coarctation in this age group who have undergone resection at St. Thomas' Hospital are described. One patient died at operation and one other has required a second operation to relieve restenosis of the anastomosis. The advisability of banding the pulmonary artery at the time of resection of coarctation complicated by other left-to-right shunts is suggested.
\end{abstract}

While the position of surgery in the management of coarctation of the aorta in older children and adults is established, the ideal approach to infants under 6 weeks with this abnormality is less well defined. The crucial decision is whether to operate and, if so, when to do so. The picture has been confused by differing methods and variable degrees of success in different units for both medical and surgical management of the problem. As many patients with coarctation survive infancy without being diagnosed, the mere presentation of such an infant places it immediately in a critical group. The mildest of these will survive with the removal of precipitating factors such as a respiratory infection or with medical treatment only. Various authors (Lang and Nadas, 1956 ; Burford, Ferguson, Goldring, and Behrer, 1960) have shown that this group tends to consist of simple coarctations with no complicating factors, although simple coarctation is no guarantee of the infant's being in this medically salvable group (Burford et al., 1960).

When full cardiological assessment has shown the infant to have a coarctation only, the policy of persisting with medical treatment before advocating surgery is justified. When other complicating lesions are present, surgery is likely to be required.

The object of this presentation is to describe the operative and post-operative course of five patients with coarctation under the age of 6 weeks to illustrate the problems involved in this difficult age group.

Correspondence : M. V. Braimbridge, St. Thomas' Hospital, London, S.E.1

\section{CASE REPORTS}

CASE 1 H.E., a 5-week-old male twin, was born three weeks prematurely and weighed $3 \mathrm{lb} .10 \mathrm{oz}$. $(1.6 \mathrm{~kg}$.$) . After two weeks of good weight gain, he$ started to feed more slowly. At the age of 1 month he had a cyanotic attack, following which he remained cyanosed and was treated with digoxin and mersalyl. On examination at 6 weeks the child was underweight and slightly jaundiced, peripherally cyanosed and dyspnoeic, had a pulse rate of 150 per minute with marked supra-sternal pulsations and diminished and delayed femoral pulses. He had an enlarged liver and spleen. The systolic blood pressure in the arms was $240 \mathrm{~mm}$. $\mathbf{H g}$. On auscultation a coarctation murmur was heard over the back of the chest. An ECG showed left ventricular hypertrophy and the chest radiograph showed a marked increase in the ventricular mass. He had been treated medically for two weeks before admission but an hour after admission he had a cardiac arrest from which he was successfully resuscitated within one minute. Medical treatment was continued with digoxin and diuretics as before, to which was added oxygen, reserpine, morphine and phenobarbitone. A slight improvement in his condition occurred over the following 24 hours but was not maintained and operation was performed the next day.

At operation a coarctation with a $1 \mathrm{~mm}$. lumen was situated opposite an obliterated ductus. The coarctation was resected and the aorta re-anastomosed with an anterior continuous suture of $5 / 0$ silk and posterior interrupted sutures. He had a smooth postoperative recovery and was taken off digoxin 10 days later and at discharge had a blood pressure of 170 / $30 \mathrm{~mm}$. $\mathrm{Hg}$.

Five years later the patient was asymptomatic, had a blood pressure of $140 / 70 \mathrm{~mm}$. $\mathrm{Hg}$ and had easily palpable femoral arteries in which the pulses were not delayed. 
CASE 2 D. M. was a 3-week-old male baby. After foetal distress in the second stage of labour, the baby suffered a period of white asphyxia after a threeweek premature birth, following which regular respiration was not achieved for $5 \frac{1}{2}$ minutes. After continued cyanotic attacks with poor feeding he was transferred to this hospital on the tenth day.

On admission he was found to be dyspnoeic with slight central cyanosis, the peripheral pulses were poor and the femoral pulsation was markedly diminished in volume. The systolic blood pressure in the arms was $95 \mathrm{~mm}$. $\mathrm{Hg}$ and in the legs $55 \mathrm{~mm}$. $\mathrm{Hg}$. The liver was enlarged three fingers' breadth. On auscultation a loud systolic murmur was heard which was maximal at the left sternal edge. The child was treated immediately with digoxin, diuretics, Edusol feeds, and oxygen, which was followed by a slight improvement over five days.

The ECG showed sinus rhythm at 120 beats per minute and mild hypertrophy of the right and left ventricles with a QRS axis of $160^{\circ}$. The chest radiograph showed a large right atrium. Catheterization and cineangiography showed a preductal coarctation, a patent ductus arteriosus and an atrial septal defect without a significant shunt. The right ventricular pressure was $60 / 5 \mathrm{~mm}$. $\mathrm{Hg}$ and the pulmonary artery pressure was $50 / 30 \mathrm{~mm}$. $\mathrm{Hg}$.

At operation on the 22 nd day there was a preductal coarctation with a $2 \mathrm{~mm}$. lumen and a $4 \mathrm{~mm}$. diameter persistent ductus arteriosus. The duct was ligated and the coarctation resected. The aorta was anastomosed with $5 / 0$ silk, with continuous over and over sutures on the right and interrupted sutures on the left.

Post-operatively he made good progress with a systolic blood pressure in the arms of $120 \mathrm{~mm} . \mathrm{Hg}$ and easily palpable femoral pulses. Six months later, however, he had deteriorated with persistent chest infections and was readmitted in heart failure. His femoral pulses had become increasingly difficult to feel. After a month's intensive medical treatment, during which time he improved clinically and his liver became smaller, a second operation was performed.

At operation a thick mass of fibrous tissue was found around the anastomosis. Its lumen was reduced to $1.5 \mathrm{~mm}$. in diameter, but was patent and contained no clot. Resection and re-anastomosis was carried out with continuous $5 / 0$ silk posteriorly and interrupted silk anteriorly.

Three years after the second operation the patient was well with equal blood pressure in the arms and legs, a murmur from the coarctation and no other physical signs.

CASE 3 S. L., a 5-week-old baby girl, was a poor feeder and failed to gain weight, becoming exhausted and slightly dyspnoeic during breast feeding.

On admission to hospital she was found to have a respiratory rate of 80 per minute with indrawing of the ribs and a prominent praecordium. The pulse rate was rapid and no femoral pulses were palpable. The liver was enlarged to one finger's breadth below the costal margin. On palpation there was moderate right ventricular hypertrophy. On auscultation at the pulmonary area there was a moderate systolic murmur and a single second sound.

The ECG showed sinus rhythm with a QRS axis of 110 degrees. The chest radiograph showed severe pulmonary plethora, mild increase in size of the right atrium and marked ventricular enlargement. At cardiac catheterization the pressure in the right atrium was a mean of $11 \mathrm{~mm}$. $\mathrm{Hg}$ and in the left atrium a mean of $15 \mathrm{~mm}$. $\mathrm{Hg}$. The pressures in the right ventricle were $80 / 12 \mathrm{~mm}$. $\mathrm{Hg}$, in the pulmonary artery $75 / 25 \mathrm{~mm}$. $\mathrm{Hg}$ and in the left ventricle $90 / 20 \mathrm{~mm}$. $\mathrm{Hg}$. Angiography showed a coarctation distal to the left subclavian artery with a large left-to-right shunt at the ventricular level. The oxygen saturation recorded in the superior vena cava was $61 \%$. in the right atrium $77 \%$, and in the right ventricle $95 \%$

At operation at 5 weeks there was narrowing of the aorta to half size immediately distal to the left $\rightarrow$ common carotid artery and a further narrowing to a $2 \mathrm{~mm}$. lumen immediately distal to the left subclavian artery. The ligamentum arteriosum was obliterated. $\vec{\theta}$ Resection of the coarctation and re-anastomosis of the aorta with $4 / 0$ Mersilene sutures, interrupted anteriorly, produced a lumen of $80 \%$ of the arch lumen.

Opening the pericardium revealed a corrected transposition of the great arteries. The pulmonary artery was banded until the mean pulmonary artery pressure was reduced from 60 to $35 \mathrm{~mm}$. $\mathrm{Hg}$ and the right ventricular pressure rose from 60 to $120 \mathrm{~mm}$. $\mathrm{Hg}$.

Post-operatively lung complications necessitated a tracheostomy for three weeks, following which she progressed well and three months later she was gaining weight and was discharged on digoxin. At followup two years later she was slightly cyanosed but growing well with palpable femoral pulses.

CASE 4 C. G., a 6-day-old baby girl, was well until the third day of life, when she had a cyanotic attack during a feed, after which she remained cyanosed. On examination at 4 days she was still cyanosed and had a pulse rate of 160 with absent femoral pulses. The liver was increased in size four fingers' breadth below the costal margin and the spleen one finger's breadth. Cardiac impulses showed marked cardiac enlargement and marked ventricular enlargement, but $\mathscr{\sigma}$ there were no thrills. In the pulmonary area there $N$ was a systolic ejection murmur followed by a widely split second sound. In the mitral area there was a soft mid-diastolic murmur.

The ECG showed sinus rhythm, left ventricular 0 hypertrophy and a mean QRS vector of $60^{\circ}$. The $\frac{}{\Phi}$ chest radiograph showed cardiac enlargement with pulmonary plethora. Cardiac catheterization showed 0 the right and left atrial pressures to be raised and $\bar{O}$ equal. The pressures in the pulmonary artery were $\overrightarrow{\mathbb{D}}$ $70 / 30 \mathrm{~mm} . \mathrm{Hg}$, in the ascending aorta $70 / 40 \mathrm{~mm} . \mathrm{Hg} \frac{\rho}{\mathbb{Q}}$ and in the descending aorta $50 / 36 \mathrm{~mm}$. Hg. Satura- \& tion in the superior vena cava was $43 \%$, in the left atrium $80 \%$, in the right atrium $70 \%$, in the aortic arch $90 \%$, and in the descending aorta $75 \%$. con- 
firming atrial and ventricular septal defects. Angiocardiography showed a patent ductus arteriosus, a preductal coarctation of the aorta and a single large coronary artery.

At operation a preductal coarctation $1 \mathrm{~cm}$. long and with a $1 \mathrm{~mm}$. lumen was resected. The aorta was re-anastomosed with $5 / 0$ silk, the ductus was ligated and the pulmonary artery banded until a mean pressure of $25 \mathrm{~mm}$. $\mathrm{Hg}$ was reached in the distal pulmonary artery.

Post-operatively a tracheostomy and positive pressure ventilation was necessary for 14 days. Thereafter she was maintained on digoxin until follow-up at 6 months when she was well enough to dispense with all drugs.

CASE 5. B. C., a 3-week-old baby girl, was born prematurely at the 36 th week; she was slow to breathe and had a mild transient jaundice. She gained weight well for six days, but then started to have cyanotic attacks, became breathless and fed poorly. She was pale and cyanosed without oxygen and a day later showed intercostal and subcostal recession. The chest radiograph at this time showed an enlarging heart and by the eleventh day of life there was some oedema.

On transfer to this hospital on the twentieth day of life she was found to be dyspnoeic, cyanosed, and to have a raised jugular venous pressure. She had delayed femoral pulses and a moderate increase in the left ventricular impulse which was displaced laterally. A pan-systolic murmur, maximal at the left sternal edge, and a continuous murmur under the left clavicle were heard on auscultation. The liver was one finger's breadth below the costal margin and there were crepitations at both bases. From the tenth day the child had been treated with frusemide and digoxin.

The electrocardiogram showed sinus rhythm at a rate of 180 and a QRS axis of $150^{\circ}$, with no ventricular hypertrophy. The chest radiograph showed a moderate increase in the size of the right atrium, right ventricle, pulmonary artery and left atrium. There was considerable pulmonary plethora.

Cardiac catheterization showed a preductal coarctation, a patent ductus arteriosus, an atrial septal defect and a large ventricular septal defect, the right ventricular pressure being $80 / 0-20 \mathrm{~mm} . \mathrm{Hg}$ and left atrial pressure $20 \mathrm{~mm}$. Hg. The oxygen saturation rose from $55 \%$ in the superior vena cava to $73 \%$ in the right atrium and $88 \%$ in the right ventricle.

At operation, resection of a $2.5 \mathrm{~cm}$. length of preductal coarctation with a lumen of $2 \mathrm{~mm}$. was carried out and the ductus was ligated. The heart, which gradually slowed during the operation, stopped as the clamps were removed and could not be started again. Necropsy gave no further information.

\section{DISCUSSION}

Surgical treatment for coarctation of the aorta in infants in cardiac failure has become accepted practice. This has been because of the publication by many authors of comparable series of infants treated both medically and surgically (Mortensen, Cutler, Rumel, and Veasy, 1959; Burford et al., 1960 ; Mustard, Rowe, Keith, and Sirek, 1955; Waldhausen, King, Nahrwold, Lurie, and Shumacker, 1964 ; Sinha, Kardatzke, Cole, Muster, Wessel, and Paul, 1969). The reservations of those less enthusiastic about the necessity for surgery in these patients tended to be based on relatively atypical groups. Lang and Nadas (1956) saved nine infants in failure due to coarctation with medical treatment alone, but all had simple coarctations with no complicating factors. Freundlich had the same success with eight other infants, again with simple coarctation only (Freundlich, Engle, and Goldberg, 1961). Schuster and Gross (1962) noted no deaths in simple coarctation in infancy managed medically over a 15-year period.

Coarctation complicated by other defects is a quite different problem. Waterston and Aberdeen (1966) described a series of 112 infants who were ill enough to require treatment for preductal coarctation. Only nine had simple coarctation. Burford's animal experiments support the lethal nature of adding a persistent ductus to a simple coarctation preparation (Burford et al., 1960). When Freundlich applied medical treatment to 19 infants with other complications in addition to the coarctation, 12 died (Freundlich et al., 1961). Sinha had no survivors in this group (Sinha et al., 1969). This survival rate is bettered by many surgical series and could be as high as $78 \%$ (Mortensen et al., 1959 ; Burford et al., 1960 ; Waldhausen et al., 1964; Pelletier, Davignon, Ethier, and Stanley, 1969 ; Sinha et al., 1969).

The problem of management of coarctation in infancy has then two facets. Simple coarctation can be treated medically with a good chance of success but may require surgery. Coarctation associated with other cardiac defects is unlikely to respond to medical treatment but can be treated surgically, though with a significant mortality.

Infants with coarctation complicated by a ventricular septal defect and a left-to-right shunt are managed at St. Thomas' Hospital by banding the pulmonary artery in addition to resection of the coarctation. In a review of the literature only two authors make any mention of this procedure (Waterston and Aberdeen, 1966 ; Pelletier et al., 
1969). Many authors draw no distinction in their results between the various anomalies that make up the 'complicated' group, which makes it difficult to compare the effects of banded with unbanded 'complicated' coarctations. The analysis of the results of three 'complicated groups' shows an overall mortality of $45 \%$ (Waldhausen et al., 1964 ; Pelletier et al., 1969). In our limited series only one (Case 1) was 'simple'. Of the four 'complicated' cases three survived, of which two had ventricular septal defects and were banded. It is possible that the addition of this technique to the resection of the coarctation will substantially reduce the mortality in this 'complicated' group.

The position of the persistent ductus has always been recognized as crucial to the prognosis. The poor results of preductal coarctation, both in dog experiments (Burford et al., 1960) and at operation (Burford et al., 1960 ; Waterston and Aberdeen, 1966 ; Mustard et al., 1955), are usually attributed to the increased incidence of other cardiac abnormalities in this group. One of the preductal coarctations died in this series. The fact that the two survivors had their pulmonary arteries banded suggests that a more effective treatment of the complications of the preductal coarctation may improve their chance of survival.

Recurrence of the narrowing at the site of the anastomosis (restenosis) is a problem that has attracted the attention of several authors. Rathi and Keith (1964) operated for coarctation on 27 infants under the age of 1 year without any restenosis. Parsons and Astley (1966) were less fortunate with 5 coarctations restenosing out of the 10 who survived the operation. D'Abreu and Parsons (1956) and Mulder and Linde (1959) reported cases of restenosis within a few weeks. Parsons (1967) reported a carefully observed case of restenosis ab initio. Restenosis is not confined to infants. Cerilli and Lauridsen (1965) cite examples of adults suffering from restenosis two and a half years after 'successful' operations for coarctation.

With all this conflicting evidence on the subject, it is hardly surprising that no completely satisfactory explanation of the recurrent narrowing has been put forward. A growth differential has been suggested but is, as Parsons (1967) points out, unable to explain the occurrence of this problem in adults, its random incidence, and the fact that the final restenosed lumen may be narrower than the original. Rodbard $(1956,1958)$ has suggested the Bernoulli principle as a cause of narrowing of stenotic lesions, where the pressure in the narrow section of a tube through which fluid is passing $\frac{\text { ? }}{0}$ is lower than the adjacent lengths of wider tubing. This reduction in pressure could be responsible $\frac{\bar{O}}{\overline{0}}$ for the recurrent narrowing of the coarcted seg- $\frac{\vec{\nabla}}{\sigma}$ ment. If this principle had any influence on the $\triangle$ in vivo situation, one must then explain its occurrence in so few cases and not in them all. Throm- $\overrightarrow{0}$ bus formation, another obvious possibility, has never been successfully demonstrated at re-opera- $\vec{\omega}$ tion or at necropsy and was certainly absent from our only case. Most restenosed suture lines show $\times$ merely nonspecific fibrosis and thickening (Cerilli ô and Lauridsen, 1965 ; Parsons and Astley, 1966). $\rightarrow$

The technique of suture of the anastomosis varies $\stackrel{A}{\overrightarrow{0}}$ greatly in different series. Mustard et al. (1955) $\vec{\omega}$

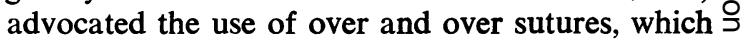
proved effective in their cases. Pelletier used three $\vec{c}$ simple continuous $5 / 0$ silk sutures in his series (Pelletier et al., 1969). Of the 22 infants who sur- vived operation, none needed re-operation. Eleven $\vec{\bullet}$ of these were subjected to serial biplane arterio-. graphy and all 11 had an anastomosis to adjacent aorta ratio of more than $45 \%$. Six were more than $55 \%$ and three more than $70 \%$. As Gupta and Wiggers (1951) and Clatworthy, Sako, Chis- ֶ holm, Culmer, and Varco (1950) have shown, $\mathbb{\perp}$ strictures below about $50 \%$ of normal are needed $\Rightarrow$ to precipitate haemodynamic changes. Other $\frac{0}{3}$ authors are less informative about their suture $\vec{\partial}$ techniques, so no true comparison is possible. Parsons, however, had used both continuous and interrupted sutures on his five restenosed anastomoses but did not report what method was $\underset{x}{\sim}$ used in the cases that did not restenose. Our 0 technique has been to combine interrupted with continuous over and over suturing with $5 / 0$ silk $\delta$ and in one case $4 / 0$ mersilene. The restenosed patient came from the former group.

Whatever the aetiology of the restenosis, the incidence in this age group, according to Waterston and Aberdeen (1966), appears to be about $25 \%$. One of our four survivors restenosed and, $\sigma$ as in Waterston's series, re-operation introduced $N$ no further mortality, and the possible incidence $\underset{\mathrm{N}}{\mathrm{N}}$ of this complication should be no discouragement $\sigma$ to the surgeon. The infant is allowed to survive until he reaches an age group where resection $\stackrel{0}{\mathbb{D}}$ of a coarctation carries a negligible mortality.

Our grateful thanks are due to Dr. B. D. R. Wilson 0 and Dr. D. G. Cottom of St. Thomas' Hospital, and Dr. S. J. R. Macoun of St. Luke's Hospital, Guildford, $\stackrel{\triangle}{\Omega}$ whose patients these were.

REFERENCES

Burford, T. H., Ferguson, T. B., Goldring, D., and Behrer, M. R (1960). Coarctation of the aorta in infants: $A$ clinical and experimental study. J. thorac. cardiovasc. Surg., 39, 47. 
Cerilli, J., and Lauridsen, P. (1965). Reoperation for coarctation of the aorta. Acta chir. scand., 129, 391.

Clatworthy, H. W., Sako, Y., Chisholm, T. C., Culmer, C., and Varco, R. L. (1950). Thoracic aortic coarctation: its experimental production in dogs, with special reference to technical methods capable of inducing significant intraluminal stenosis. Surgery, 28, 245.

D'Abreu, A. L., and Parsons, C. (1956). Surgical treatment of children with coarctation of the aorta. Brit. med. J., 2, 390.

Freundlich, E., Engle, M. A., and Goldberg, H. P. (1961). Coarctation of aorta in infancy. Analysis of a 10-year experience with medical management. Pediatrics, 25, 427.

Gupta, T. C., and Wiggers, C. J. (1951). Basic hemodynamic changes produced by aortic coarctation of different degrees. Circulation, produ.

Lang, H. T., and Nadas, A. S. (1956). Coarctation of the aorta with congestive heart failure in infancy-Medical treatment. Pediatrics, 17, 45.

Mortensen, J. D., Cutler, P. R., Rumel, W. R., and Veasy, L. G. (1959). Management of coarctation of the aorta in infancy. J. thorac. Surg., 37, 502.

Mulder, D. G., and Linde, L. M. (1959). Recurrent coarctation of the aorta in infancy. Amer. Surg., 25, 908.

Mustard, W. T., Rowe, R. D., Keith, J. D. and Sirek, A. (1955), Coarctation of the aorta with special reference to the first yea of life. Ann. Surg., 141, 429.
Parsons, C. G. (1967). Recurrent coarctation of the aorta. Amer. Heart J., 73, 1.

- and Astley, R. (1966). Recurrence of aortic coarctation after operation in childhood. Brit. med. J., 1, 573.

Pelletier, C., Davignon, A., Ethier, M., and Stanley, P. (1969). Coarctation of the aorta in infancy. Postoperative follow-up. J. thorac. cardiovasc. Surg., 57, 171.

Rathi, L., and Keith, J. D. (1964). Post-operative blood pressures in coarctation of the aorta. Brit. Heart J., 26, 671.

Rodbard, S. (1956). Vascular modifications induced by flow. Amer. Heart J., 51, 926.

- (1958). Physical factors in the progression of stenotic vascular lesions. Circulation, 17, 410.

Schuster, S. R., and Gross, R. E. (1962). Surgery for coarctation of the aorta. A review of 500 cases. J. thorac. cardiovasc. Surg., 43, 54 .

Sinha, S. N., Kardatzke, M. L., Cole, R. B., Muster, A. J., Wessel, H. U., and Paul, M. H. (1969). Coarctation of the aorta in infancy. Circulation, 40, 385.

Waldhausen, J. A., King, H., Nahrwold, D. L., Lurie, P. R., and Shumacker, H. B. (1964). Management of coarctation in infancy. J. Amer. med. Ass., 187, 270.

Waterston, D. J., and Aberdeen, E. (1966). Preductal coarctation of the aorta. From the Symposium on heart and circulation: The newborn section. Grune and Stratton, Chicago. 